\title{
Optimization of Reproducible Biochemical Genotype for Population: The Case of Trifolium Alexandrinum L., Fabacae
}

\author{
S. Rouz ${ }^{1}$, F. Ben Jeddi ${ }^{2}$, M.Zouaghi ${ }^{3}$, Z. Ghrabi-Gammar ${ }^{4}$ \\ ${ }^{1}$ Ecole Supérieure d'Agriculture de Mograne, 1121-El Magren, Tunisie \\ ${ }^{2,3,4}$ Institut National Agronomique de Tunisie, 43 Avenue Charles Nicolle 1082 Tunis-Mahrajène, Tunisie
}

\begin{abstract}
This study aims to optimize an experimental protocol for giving reproducible genotype of berseem populations. In total, 64 accessions of berseem clover, comprising varieties, landraces and wild forms were used. SDS-PAGE (Sodium Dodecyl Sulfate Polyacrylamide Gel Electrophoresis) technique was used and results revealed a high level of polymorphism and a major genetic difference between examined taxa. The optimization of the biochemical characterization revealed that the use of a sample of 200 seeds gives reproducible groups for each population. Efficient maintenance of genetic integrity is obtained when 200 plants are multiplied together and when seeds are collected for each plant. These regeneration strategies are discussed according to the financial and technical context of their application. These results can be used for preservation programs of different populations.
\end{abstract}

Keywords: Trifolium alexandrinum, berseem, genetic diversity, preservation program

\section{Introduction}

In Tunisia, berseem (Trifolium alexandrinum L.) is considered one of the best forage plants in irrigated areas. It is a good preceding crop for spring and summer crops grown in intensive culture systems and is the main source of protein for dairy cows during the fall and spring period. Very productive and good feeding value, it suffers from some biological problems associated with morphological and biological heterogeneity (date of flowering etc.). The development of new varieties of berseem adapted to new growing areas and with high yields can be achieved through the gradual integration of genetic diversity in breeding programs. The conservation and maintenance of an important genetic diversity are essential to meet future needs of production systems. But despite the antiquity of the presence of berseem $\mathrm{s}$ in Tunisia, few studies have addressed its genetic diversity. Taking into account the literature and reproductive traits, strong hybridization frequency of native pollinators and seed dispersal, suggesting that what is called berseem today is in fact a very complex and evolving group (Rouz, 2010). . Greuter et al (1989) reported that T. L. alexandrinum is a problematic specie taxonomically distinct in four subspecies: berytheum, alexandrinum, vavilovii and serotinum. These are a very xénophyte and polymorphic species. Therefore, it becomes important to clarify the taxonomy of the biological material we have. The berseem electrophoresis analysis of total protein seeds is widely used in the classification, identification of new improved varieties and seed certification tests (Wrigley et al., 1982; Cooke, 1988 and 1989). This technique is also used in gene banks to study redundancies accessions. In this work, we analyze the genetic diversity of 64 accessions berseem available in the collection of INAT through SDS-PAGE technique.

\section{Materials and Methods}

Sixty four berseem accessions collected by the laboratory of forage and pastoral productions of INAT and stored in its index as fodder T. L. alexandrinum are characterized biochemically by means of SDS-PAGE technique. These accessions are from seven Mediterranean countries (Tunisia, Morocco, Portugal, Italy, Turkey, Palestine, Egypt) and the USA, and were collected during prospecting missions between 1981 and 1982. Others were obtained by exchange with various research institutions.

\section{a) Extraction and Denaturation Seed Total Protein}

Grinding samples berseem seeds of different accessions are effected by a vibrator oscillating mill (Retsch MM 200 Model). The extraction of the storage proteins from the flour of the seeds is carried out by a reducing agent, 2mercaptoethanol $\beta$, which reduces the disulfide bonds and gives a monomeric form, by a strong anionic detergent, the sodium dodecyl sulphate (SDS ) which envelops the polypeptide chains of the negatively charged protein by $1 \mathrm{M}$ Tris- $\mathrm{HCl} \mathrm{pH}=6.8$, for glycerol and bromophenol blue. The negative charges repel and unfolded polypeptide chains that do not therefore tend to aggregate. The extraction time is about two hours. The samples are heated for five minutes at a temperature of $95^{\circ} \mathrm{C}$. The proteins are denatured and lose their native three dimensional structure. After cooling, they are subjected to centrifugation at 14,000 revolutions / minute for five minutes at $4^{\circ} \mathrm{C}$.

\section{b) Preparation of Gel Electrophoresis}

The electrophoresis gel under denaturing conditions (Sodium Dodecyl Sulfate polyacrylamide gel electrophoresis or SDSPAGE) described by Laemmli (1970), is used to analyze the extracted storage proteins studied different accessions berseem. The presence of SDS in the gel imparts a negative charge to the protein and promotes their migration by size only. The porosity of the gel is provided by the bond between the side chains of acrylamide and bridges formed by bis- 


\section{International Journal of Science and Research (IJSR) \\ ISSN (Online): 2319-7064 \\ Index Copernicus Value (2013): 6.14 | Impact Factor (2014): 5.611}

acrylamide. The size of the pores of the polymerized gel can vary from 0.85 to $210-7 \mathrm{~cm}$ and it is reduced as a function of bisacrylamide rate relative to acrylamide. This electrically inert matrix does not affect the migration and allows highresolution separations.

The gel is formed by:

- A separating gel containing $30 \%$ acrylamide, $2 \%$ bisacrylamide, $1 \mathrm{M}$ Tris- $\mathrm{HCl} \mathrm{pH}=8.8$ and $10 \%$ SDS. The polymerization reaction is initiated by means of $3 \%$ ammonium persulfate (APS) and TEMED-catalyzed (N, N, $\mathrm{N}$ ', N'-tetramethyl-1-, 2-diaminomethane). It is poured between glass plates, $70 \times 110 \mathrm{~mm}$ spaced $1 \mathrm{~mm}$ to $3 \mathrm{~cm}$ from the top, fixed on a support. Degassing is performed to remove air bubbles. The gel was then covered with distilled water for half an hour, period required for polymerization.

- A stacking gel containing 30\% acrylamide, $2 \%$ bisacrylamide, Tris- $\mathrm{HCl} \mathrm{pH}=6.8,3 \%$ ammonium persulfate, TEMED and $10 \%$ SDS is added above the gel separation. In this experiment, we used a high acrylamidebisacrylamide percentage to have a high channel density and the tight mesh network.

\section{C) Migration Electrophoresis}

The glass plates containing the polymerized gel are placed in an electrophoresis tank with four cassettes equipped with a cooling system. A volume of 6 .mu.l of the extract proteins to be separated is deposited in each well for all samples representative of the population. Two repetitions were performed by accession. For the SDS-7 marker size, a volume of 3 .mu.l was filled.

A conductive electrophoresis buffer (3 g Tris, 14,1g Glycine (weak acid), $10 \mathrm{ml} \mathrm{10 \%} \mathrm{SDS} \mathrm{in} 1000 \mathrm{ml}$ of distilled water; $\mathrm{pH}=8.3$ ) is placed in the vessel and migration of denatured proteins deposited in the wells is carried out under the action of an electric field.

A pre-migration occurs under a potential difference of $300 \mathrm{~V}$, a $120 \mathrm{~mA}$ current intensity and power of $100 \mathrm{~W}$ for the stacking gel, and this for 15 minutes. Then, to the separation gel migration, the intensity is doubled to $240 \mathrm{~mA}$ while keeping the same electrical potential difference and the same power. The total duration of the electrophoresis is between one hour thirty five minutes to two hours.

\section{d) Fixing and staining the gel-}

After migration, the gel is removed from the mold, and only the separation gel is used. Proteins were fixed to the gel in the presence of trichloroacetic acid (TCA) (15\%) during 30 minutes. TCA irreversibly denatures proteins in the meshes of the gel. They are revealed by staining with Coomassie Brilliant Blue Serva Blue G (SBG) and Serva Blue R (SBR) ( $1 \%$ solution in methanol), overnight at room temperature using a three-dimensional agitator. Various bands were obtained. The molar mass of the proteins is determined by SDS-7 marker (Sigma) having known molecular weights of standard proteins ranging from 14 to $70 \mathrm{kDa}$. These proteins are: Albumin Bovine (66 kDa), ovalbumin (45 kDa), glyceraldehyde-3-P-dehydrogenase $(36 \mathrm{kDa})$, Carbonic
Anhydrase Bovine (29 kDa), bovine pancreatic trypsinogen $(24 \mathrm{kDa})$, trypsin inhibitor soy $(20 \mathrm{kDa})$ and $\alpha$-lactalbumin bovine milk (14.2 kDa). Gels were photographed and analyzed by BioCapt program.

\section{e) Development of the electrophoresis protocol}

To ensure the reproductive system and developing an effective biochemical characterization protocol, total protein seed of 64 accessions studied berseem were extracted from samples of size 5 seeds and 200 seeds. Three volumes of extract was tested as follows: 5, 6 and $10 \mu 1$.

An increase in the 30 minute duration of migration was performed using the total proteins extracted from a sample of 200 seeds and louse improve the resolution between the berseem electrophoresis bands generated.

\section{f) Analysis of berseem electrophoresis bands}

The results of electrophoresis are read on the pictures of the gels. Only clearly visible bands were recorded. The profiles have been transformed into binary matrices presence (1) or absence (0) of bands on lines studied accessions and columns berseem electrophoresisprotein bands generated by the SDSPAGE technique. The matrices of data were analyzed by the program "Treecon for Windows" (Sokal and Sneath, 1973) according to UPGMA method (unweighted Pair-Group Method using Arithmetic Average) Nei and Li (1979). Dissimilarity matrix is calculated and the distance dendrogram was constructed.

\section{Results and Discussion}

\section{Optimizing the biochemical characterization method of berseems}

The electrophoresis method used for variety identification differs from one specie to another according to its reproduction system (Cooke, 1988). This work was done to optimize the methods for biochemical characterization of accessions berseem. The technique adopted is the technique of ISTA (1999) to which we have made changes. Net berseem electrophoresis bands are obtained with 6 .mu.l seed extract total protein. The different gels obtained to study the biochemical variability of 64 accessions berseem are shown in Figure 1. The total proteins were well separated and the representative strips of different masses of proteins are determined using markers SDS-size 7 .

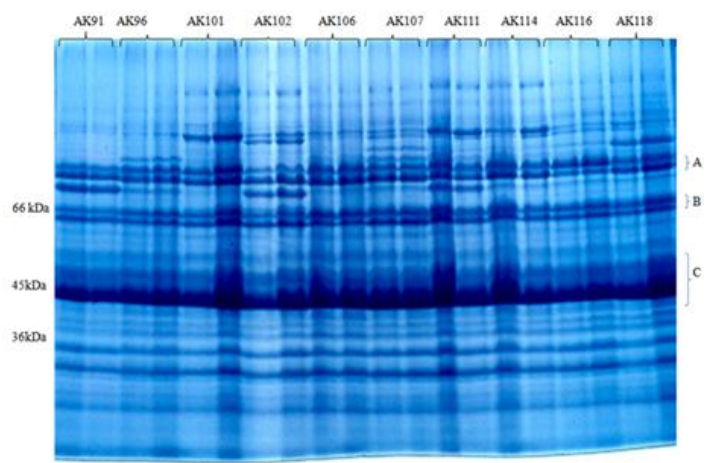

Figure 1: Electrophoresis profiles of total proteins extracted from seeds and 200 obtained for the 64 accessions berseem through SDS-PAGE Technical 


\section{International Journal of Science and Research (IJSR) \\ ISSN (Online): 2319-7064}

Index Copernicus Value (2013): 6.14 | Impact Factor (2014): 5.611

\section{Standardization of Regenerated Sample Size}

Berseem conservation in seed gene banks is to maintain genetic diversity that will eventually be used to plant breeders and biotechnologists. Ex situ conservation efficient depends on maintaining the genetic integrity of the original accessions. Smaller populations are vulnerable to loss of biodiversity during regeneration, since few individuals contribute to the next generation.

For regeneration of cross-pollinated varieties, the registrar shall determine the optimal size of the representative sample of the total variability of the accession taking into account both the risk of genetic drift that the cost of the operation. The direct approach multilocus adopted in this work, using electrophoresis of total protein of seeds genetically encoded by more than one locus which shows a substantial polymorphism, is a recognized approach to analyze the genetic diversity of plant species.

Regarding accessions berseem considered in this study that were found to be pollinated and entomophilies, the use of an effective size of 200 seeds appears optimal to limit genetic drift and maintain a sufficient level of genetic diversity within the collection. The below reduction of the number of plants to regenerate population could lead to loss of biodiversity. This size is sufficient to retain more than 20000 polymorphic loci when the allelic frequency is less than 0.05 . It is difficult to keep all the alleles, as this requires a very large population and hence a very high cost of the operation. Our results are consistent with those of Lawrance et al., (1995) that recommend the use of hundred and seventy two seeds collected from hundred and seventy two different plants to maintain genetic variability at large in a crosspollinated species population. The inter-crossing between these individuals gives an equilibrium population HardyWeinberg.

\section{Conclusion}

Biochemical characterization of 64 accessions berseem by SDS-PAGE technique has identified net genetic diversity of biological material. The SDS-PAGE technique has proven to be effective in the classification, identification, safeguarding and maintenance "ex situ" of the genetic diversity of accessions berseem. The results confirm that berseem is a cross-pollinated species and the use of a sample size of 200 seeds gives identical protein profiles and reproducible for the same assumption. This size includes the majority of the genes and alleles representing all of the variability of accession. The preservation of a tank, where variability is the widest available, is a guarantee for the future of the selection.

\section{References}

[1] Cooke, R.J., 1988. Electrophoresis in plant testing and breeding. Advance in Electrophoresis.2, 171-261.

[2] Cooke, R.J., 1989. The use of electrophoresis for the distinctness testing of varieties of autogamous species. Plant Varieties and Seeds, 2, 3-13.
[3] Greuter, W., M.H. Burdet \& G. Long, 1989. MedChecklist. Dicotylédones (Lauraceae-Rhamnaceae). 4, Conservatoire et jardin Genève ed., 132-134.

[4] International Seed Testing Association (ISTA), 1999. International rules for seed testing. Seed Science and technology, 27 (Supplement).

[5] Laemmli, UK., 1970. Cleavage of structural proteins during the assembly of the head of bacteriophage T4. Nature 227 :680-685.

[6] Lawrence, M.J., D.F. Marshall \& P. Davies, 1995. Genetics of genetic conservation. II. Sample size when collecting seed of cross-pollinating species and the information that can be obtained from the evaluation of material held in gene banks. Euphytica 84: 101-107.

[7] Nei, M. \& W. Li, 1979. Mathematical model for studying genetic variation in terms of restriction endonucleases. Proc. Natl. Acad. Sci. USA. 76:52695273.

[8] Rouz, S., 2010. Diversité agronomique et biologique du trèfle d'Alexandrie (Trifolium alexandrinum L.) et création de variétés synthétiques. Thèse de doctorat en sciences Agronomiques de l'INAT. p.193.

[9] Sneath, P.H.A \& R.R. Sokal, 1973. Numerical taxonomy. The principles and practice of numerical classification. San Francisco: Freeman, 573 p.

[10] Wrigley, C.W., J.C. Autran \& W. Bushuk, 1982. Identification of cereal varieties by gel electrophoresis of the grain proteins, Advances in Cereal. Science and Technology, 211-259. 